
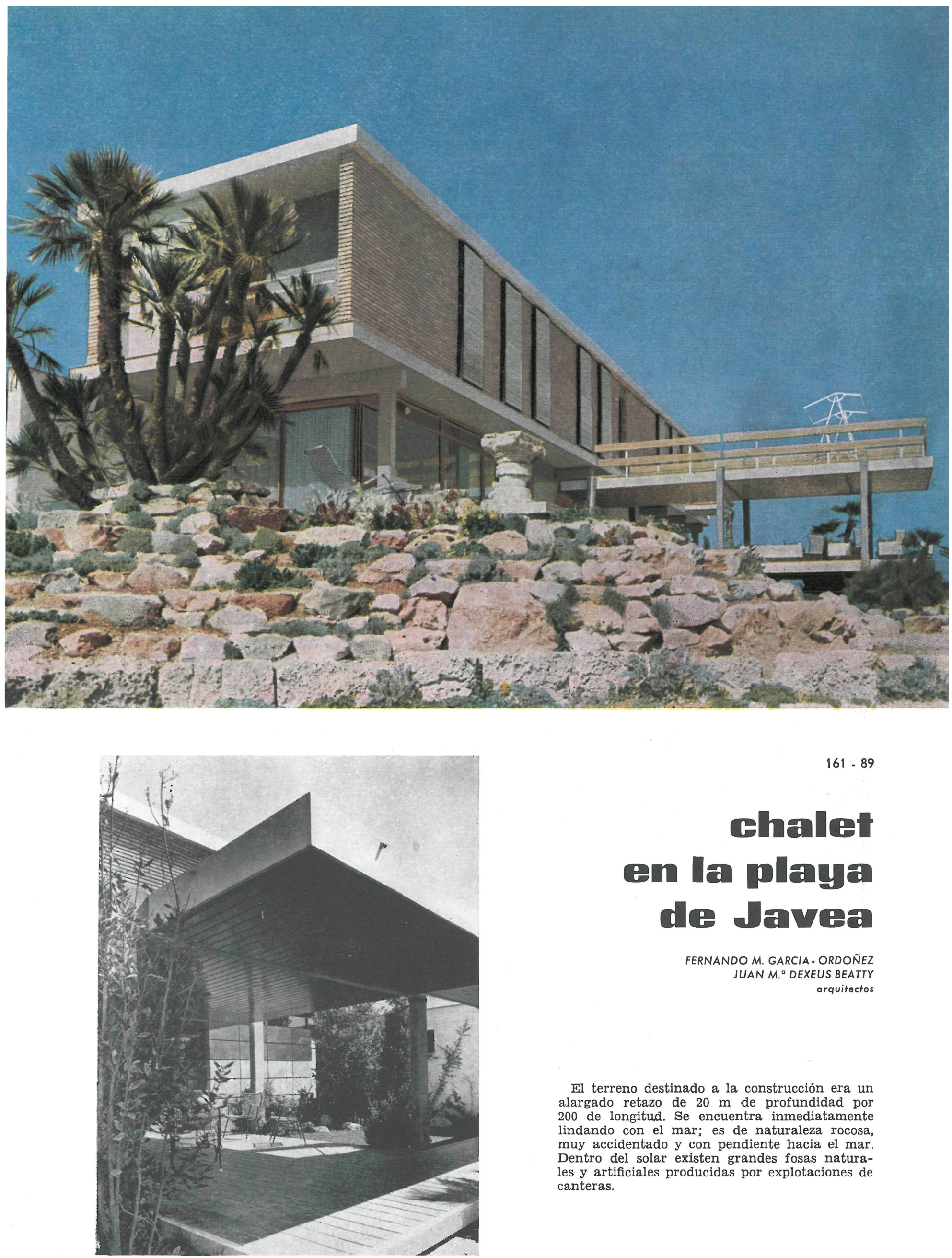

$161 \cdot 89$

\title{
chalet en la playa de Javea
}

FERNANDO M. GARCIA - ORDOÑEZ JUAN M. ${ }^{\circ}$ DEXEUS BEATTY

El terreno destinado a la construcción era un alargado retazo de $20 \mathrm{~m}$ de profundidad por 200 de longitud. Se encuentra inmediatamente lindando con el mar; es de naturaleza rocosa, muy accidentado y con pendiente hacia el mar. Dentro del solar existen grandes fosas naturales y artificiales producidas por explotaciones de canteras. 


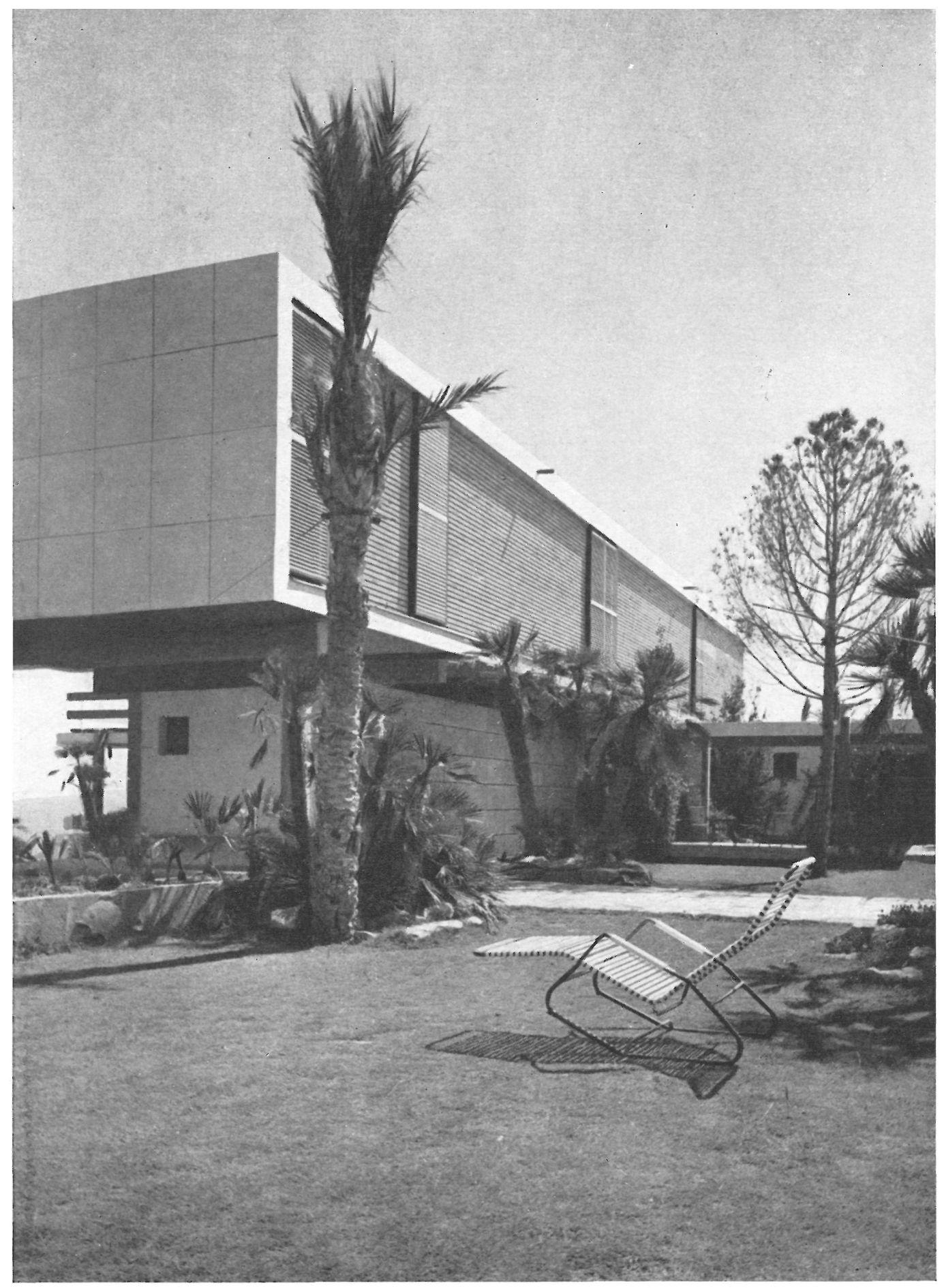

El cliente deseaba la oportunidad de vivir lo más cerca posible del mar. Buscaba vistas concretas: hacia la bahía y hacia las monta ñas de la espalda. Quería evitarse el uso de toldos por su enojosa conservación en zona azotada por los vientos; el volumen edificado debía, por tanto, sombrear los espacios exteriores al me diodía y por la tarde. También deseaba organizar zonas exteriores independientes para esta ncia que permitiesen la contemplación de panorámicas diferentes. Como las duchas y vestua rios debían situarse en el mismo edificio, exigió que tuviesen entrada independiente para evitar circulaciones por las zonas nobles de la casa. Deseaba poseer algún jardín íntimo donde se pudiera permanecer con pleno olvido del mar: ello exigiría, por consiguiente, una adecuada protección contra los vientos húmedos cargados de pulverizaciones salinas. 

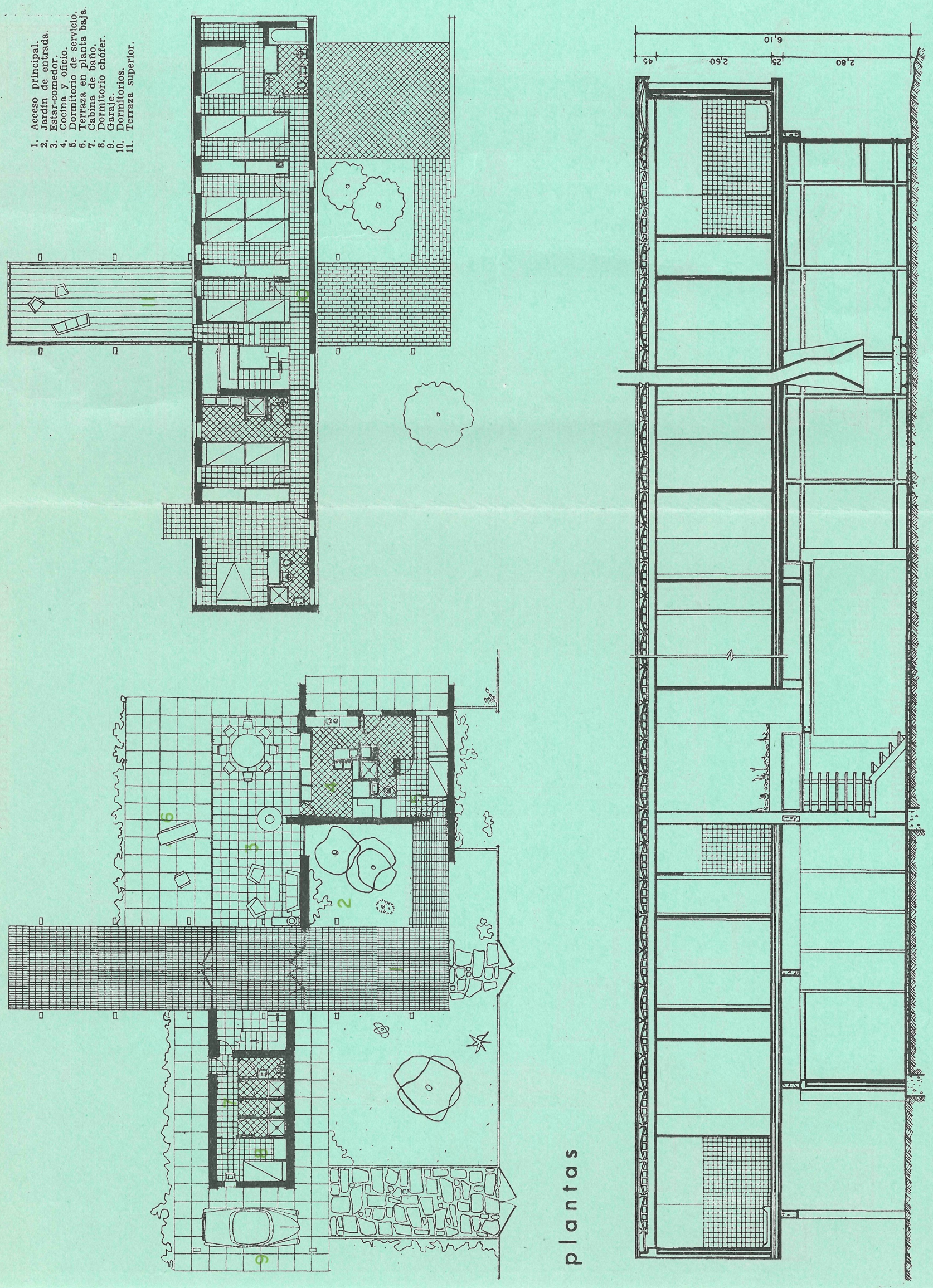

$c$
0
$u$
$u$
0
0 

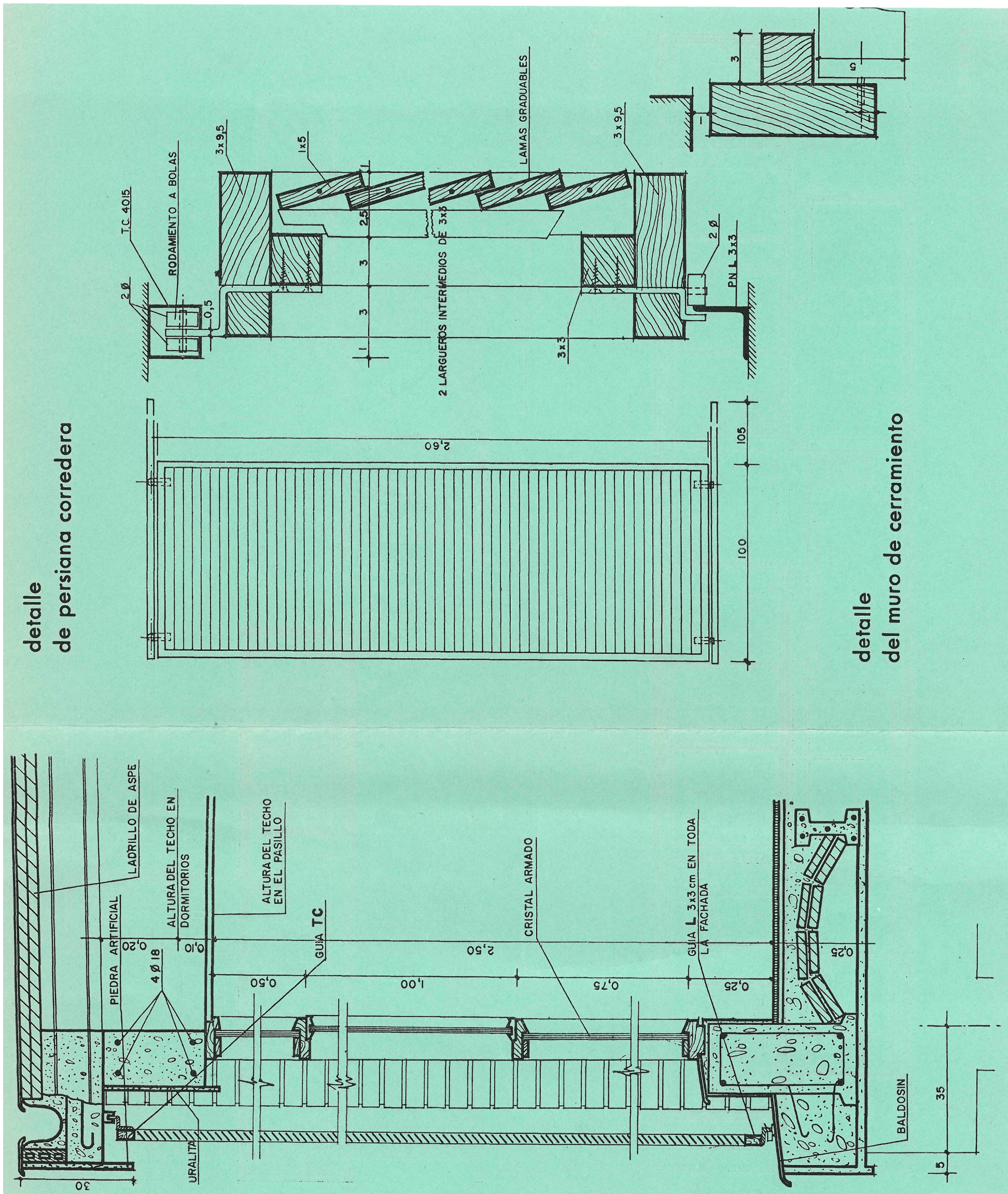
El cliente posee una numerosa familia, pero, naturalmente, quería construirse la superficie lo más escueta posible; con este objeto propuso el uso de dormitorios con literas de cuatro camas. Sólo dos habitaciones permiten la disposición normal de camas. Puesto que la vida iba a desarrollarse al aire libre en su mayor parte, deseaba además que los dormitorios se hiciesen lo menos "encontradizos" posible; se le sugirió que podrían colocarse todos ellos en una planta superior.

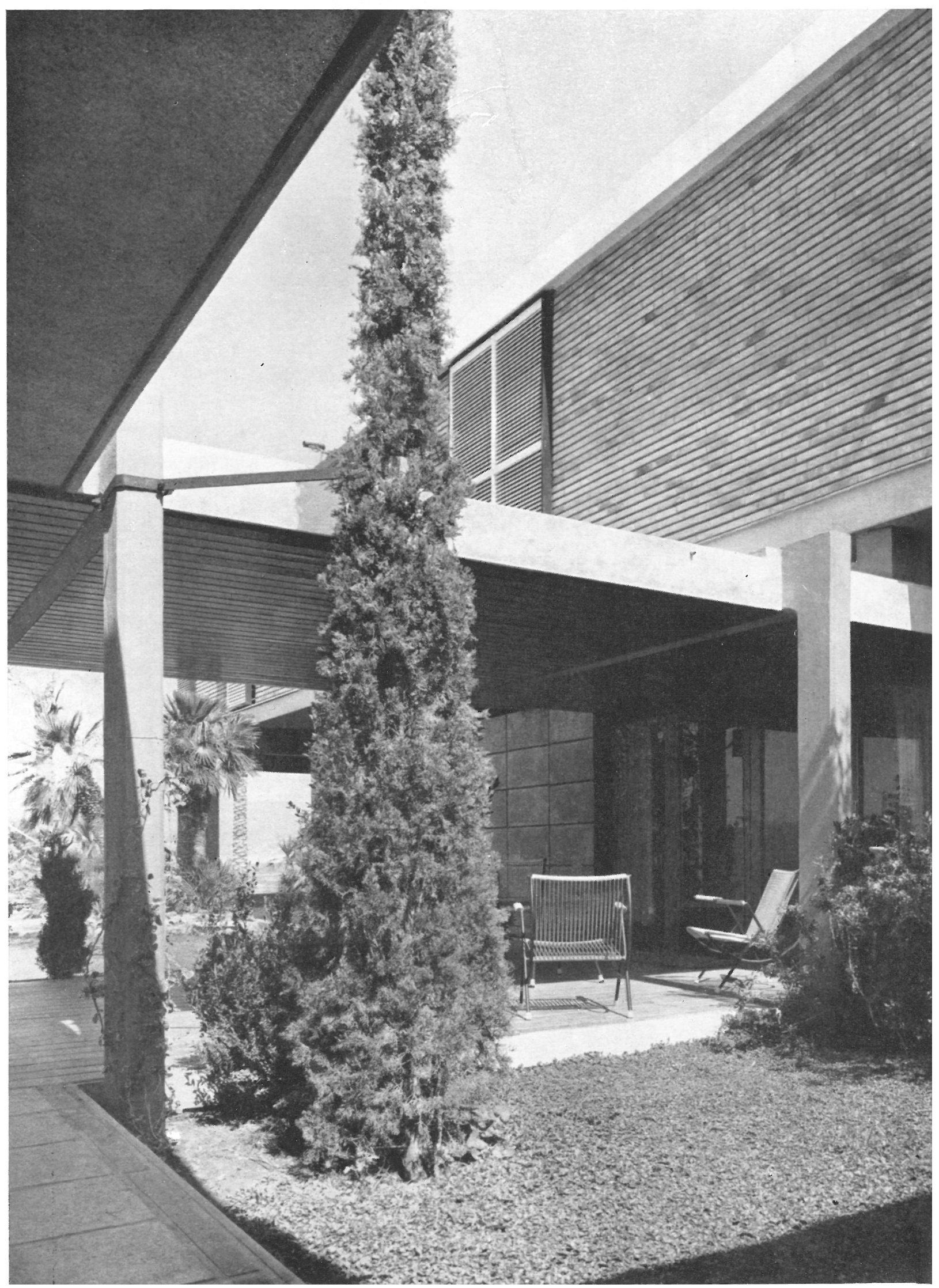




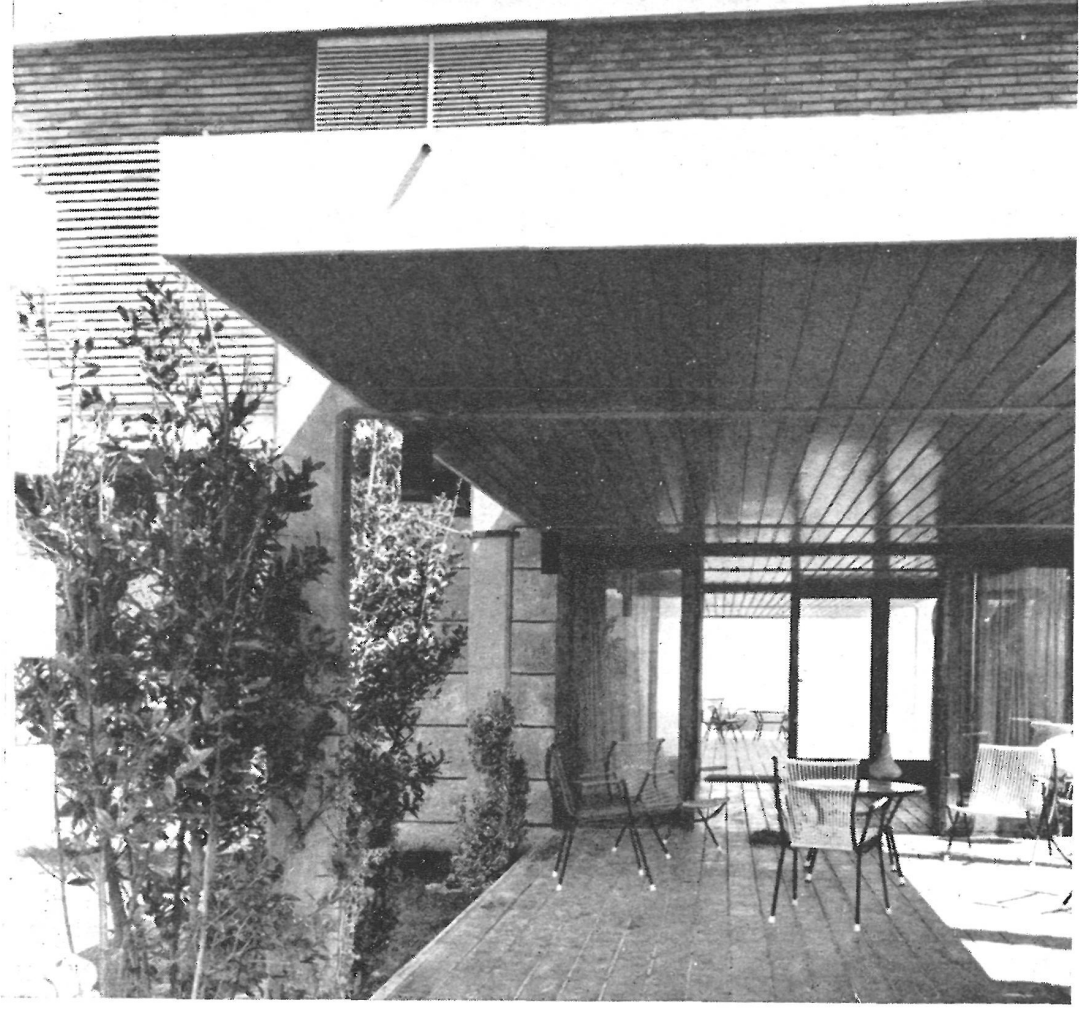

Entrada principal.

Estar-comedor.

La misma idea de vivir en contacto con la naturaleza, muy amada por el cliente, insinuó la necesidad de proyectar un edificio con el que se tropezase, física y ópticamente, lo menos posible.

Al cliente le agradaba, asimismo, la idea de que su casa no impidiese la vista del paisaje; de ahí, que su planta baja debería resultar flexible y muy transparente.

En fin: todo esto y mucho más que el cliente y familia escribieron en un largo memorándum, fue pasado a línea sobre un vegetal bajo la dirección del arquitecto.

Así fue proyectado el edificio que presentamos.

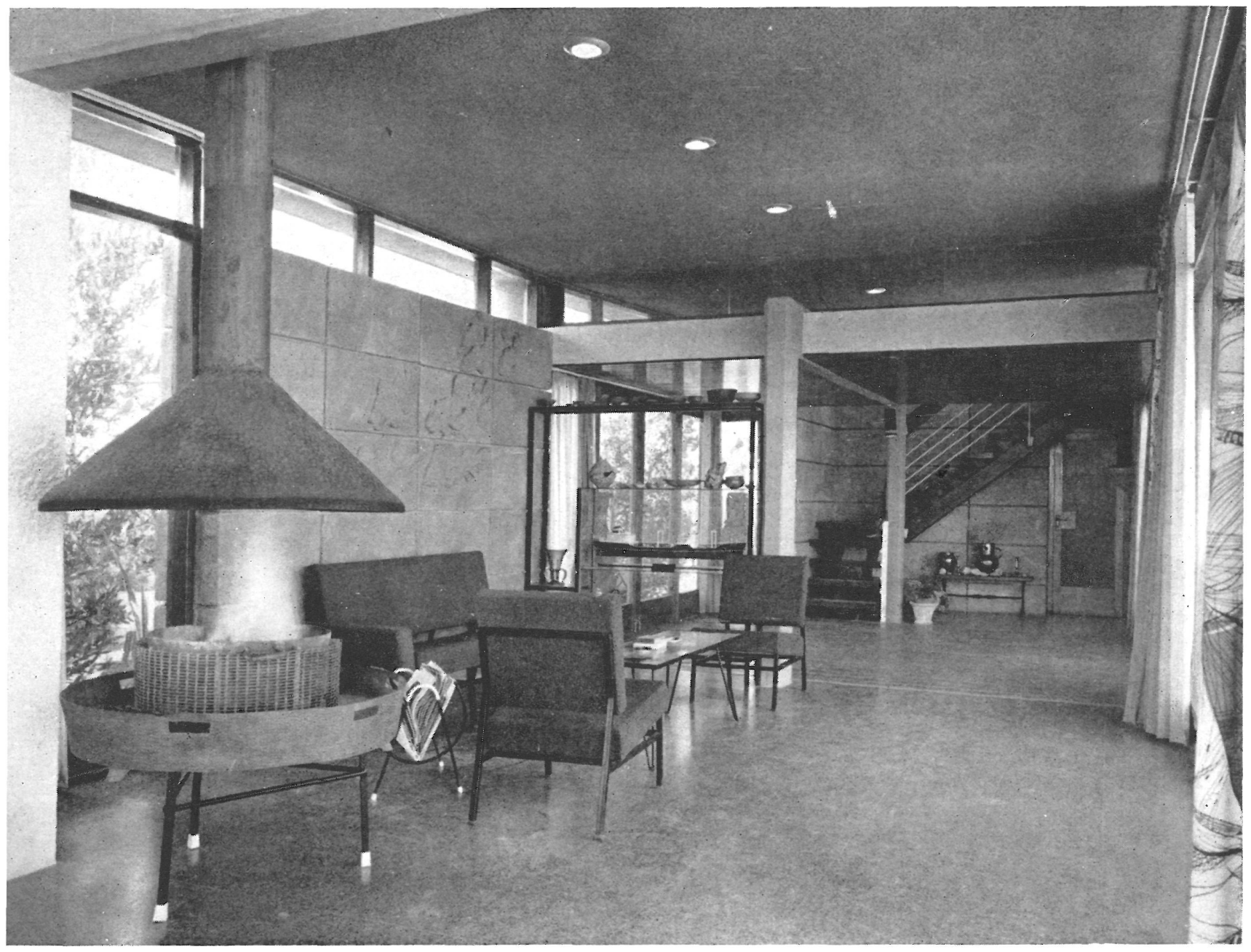

